\title{
PENYELESAIAN CAPACITATED VECHILE ROUTING PROBLEM DENGAN MENGGUNAKAN ALGORITMA SWEEP UNTUK PENENTUAN RUTE DISTRIBUSI KORAN : STUDI KASUS
}

\author{
Rizky Saraswati ${ }^{*}$, Wahyudi Sutopo ${ }^{2}$, Muh. Hisjam ${ }^{3}$ \\ ${ }^{1}$ Alumnus Program Teknik Industri, Fakultas Teknik, Universitas Sebelas Maret, Ir Sutami 36A, Surakarta, 57126, Indonesia \\ ${ }^{2,3}$ Program Studi Teknik Industri, Fakultas Teknik, Universitas Sebelas Maret, Ir Sutami 36A, Surakarta, 57126, Indonesia \\ Email: saraswatirizky@gmail.com,wahyudisutopo@gmail.com, hisjam@uns.ac.id \\ *Korespondensi
}

\begin{abstract}
Abstrak: Vehicle Routing Problem merupakan permasalahan yang berhubungan dengan penentuan rute distribusi optimal dengan melibatkan beberapa kendala untuk melayani sejumlah agen sesuai permintaan tiap agen. Capacitated Vehicle Routing Problem merupakan salah satu variasi Vehicle Routing Poblem dengan kendala kapasitas kendaraan. Tujuan dari penelitian ini berua pembentukan model Capacitated Vehicle Routing Problem pada permasalahan rute distribusi harian Solopos wilayah Kartasura-Klaten dengan algoritma sweep. Algoritma sweep terdiri dari dua tahap, yaitu clustering agen dan pembentukan rute untuk tiap agen yang telah dicluster dengan metode Nearest Neighbour. Maka didapatkan hasil berdasarkan perhitungan yang dilakukan diperoleh dua rute sesuai dengan cluster yang menempuh waktu total 5 jam 55 menit sesuai dengan kebijakan time windows yang diterapkan harian Solopos.
\end{abstract}

Kata kunci: Capacitated vehicle routing problem (CVRP); algoritma sweep; rute distribusi.

\begin{abstract}
Vehicle Routing Problem is a problem associated with determining the optimal distribution route by involving some constraints to serve a number of agents at the request of each agent. Capacitated Vehicle Routing Problem is one of the variations of Vehicle Routing Poblem with vehicle capacity constraints. The purpose of this research is the formation of Capacitated Vehicle Routing Problem model on the problem of daily distribution route of Solopos Kartasura-Klaten with sweep algorithm. Sweep algorithm consists of two stages, namely clustering agents and the formation of routes for each agent that has been clustered with Nearest Neighbors method. Then the results obtained based on the calculations is two routes in accordance with the cluster which took a total time of 5 hours 55 minutes in accordance with the time policy windows applied daily Solopos.
\end{abstract}

Keywords: Capacitated vehicle routing problem (CVRP);algoritma sweep; distribution route.

\section{PENDAHULUAN}

Suatu perusahaan yang menghasilkan suatu produk membutuhkan sistem distribusi yang baik untuk penyebarannya. Tak terkecuali bagi perusahaan yang bergerak dalam percetakan surat kabar, PT Aksara Solopos yang harus mengirimkan harian Solopos setiap harinya kepada para agen yang tersebar luas di berbagai area geografis, untuk nantinya di salurkan kepada para pembaca. Namun distribusi produk koran berbeda dengan distribusi produk lainnya. Hal ini dikarenakan distribusi koran memiliki batas waktu (time windows) dalam penyebarannya, agar berita tersebut masih tetap up to date sehingga pelanggan masih tetap setia untuk membaca.

Dalam prosesnya diperlukan manajemen rantai pasok mulai dari proses produksi, pengiriman, penyebaran dan pemasaran produk hingga sampai ke tangan pelanggan. Proses produksi dimulai pada pukul 22.00 hingga 02.30 berarti proses penyusunan dan pencarian berita pun dilakukan sebelum proses produksi dilakukan. Hal ini dikarenakan pengiriman produk dilakukan pada pukul 03.00 hingga 08.00 dengan menggunakan moda transportasi yang terbatas.

Penyebaran produk dilakukan serentak pada saat itu juga ke sejumlah agen dalam beragai lokasi berbeda.

Dengan adanya sistem distribusi, perusahaan dapat melakukan pengambilan maupun pengiriman barang dari atau untuk pelanggan yang tersebar secara geografis. Sesuai dengan permintaan yang telah ditentukan menggunakan armada sebagai sarana pengangkutan. Maka PT Aksara Solopos melakukan pengelompokkan agen dalam suatu wilayah tertentu, namun dibutuhkan penentuan rute yang baik agar waktu dan biaya operasional distribusi efektif dan efisien. Saat ini proses distribusi produk masih sebatas area wilayah tertentu dimulai dari agen terdekat namun belum memiliki rute tetap.

Pengiriman dan penentuan rute dalam distribusi koran harian Solopos ini pun memiliki beberapa masalah yaitu jumlah agen yang besar dengan cakupan yang tersebar luas membuat rute distribusi 
barang menjadi hal yang sangat penting. Perusahaan Solopos saat ini hanya melakukan pengiriman barang berdasarkan pengelompokkan wilayah agen tanpa mempertimbangkan jalur rute dan kapasitas yang digunakan.

Oleh karena itu perlu adanya keputusan operasional berkaitan dengan permasalahan. Capacitated Vechile Routing Problem. Capacitated Vechile Routing Problem merupakan permasalahan dalam penentuan rute atas distribusi ke beberapa depot/agen dengan titik awal dan akhir distribusi sama.

Batasan-batasan yang diterapkan adalah produk homogen, kapasitas kendaraan, dalam jangka time windows tertentu. Permasalahan Capacitated Vechile Routing Problem telah banyak diangkat oleh beberapa peneliti seperti Fermin dan Roberto, 2004 dalam menyelesaikan tabu search, Tavakkoli, 2005 dengan simulated annealing dan Hijri dalam penelitiannya membandingkan algoritma saving dengan algoritma sweep dalam penentuan distribusi studi kasus air mineral Club di Kota Balikpapan. Dengan hasil penelitian bahwa algoritma sweep menghasilkan solusi optimal dibandingkan dengan algoritma saving.

Dalam penelitian ini dibahas penyelesaian masalah mengenai Capacitated Vechile Routing Problem dengan menggunakan algoritma sweep pada adalah distribusi harian Solopos wilayah Kartasura-Klaten. Wilayah Klaten-Kartasura dipilih karena memiliki nilai persentase penjualan terendah dibanding wilayah Solo Raya lainnya. Diharapkan dengan menemukan rute distribusi terbaik dapat meningkatkan nilai persentase penjualan wilayah Kartasura-Klaten.

\section{KAJIAN TEORI}

\section{Vechile Routing Problem}

Vechile Routing Problem merupakan metode untuk memecahkan suatu permasalahan distribusi dengan moda kendaraan pada titik pusat tertentu/ depot dan diharuskan untuk mengunjungi tiap agen selama periode tertentu yang tersebar secara geografis untuk memenuhi kebutuhan tertentu.

\section{Tahap penyelesaian model CVRP}

Capacitated Vehicle Routing Problem merupakan salah satu permasalahan yang paling umum dari Vehicle Routing Problem, yang dideskripsikan sebagai depot centra atau pusat, yang menggunakan moda kendaran dengan kapasitas tertentu untuk melayani permintaan sejumlah agen.

Algoritma sweep merupakan suatu algoritma menggunakan metode dua fase dengan fase pertama berupa clustering pelanggan berdasarkan wilayah dan kendaraan yang tersedia, dan fase dua berupa membangun rute-rute untuk tiap cluster. Dalam menyelesaikan model CVRP dengan menggunakan algoritma Sweep diperlukan dua tahapan atau fase yaitu fase pengelompokkan (clustering) dan fase pembentukan rute:

a. Tahap pengelompokkan (clustering)

Langkah-langkah yang dilakukan pada tahap pengelompokkan adalah:

- Menentukan tiap posisi agen dalam koordinat kartesius dan menetapkan lokasi depot sebagai pusat koordinat.

- Menentukan seluruh koordinat polar tiap agen dengan depot awal.

$$
\begin{gathered}
r=\sqrt{x^{2}+y^{2}} \\
\theta=\arctan \frac{x}{y}
\end{gathered}
$$

- Membentuk pengelompokkan (clustering) dimulai dari agen yang memiliki sudut polar terkecil hingga terbesar dengan mempertimbangkan kapasitas kendaraan.

- Memastikan semua agen yang terlibat telah dikelompokkan dalam cluster ini.

- Pengelompokkan dihentikan apabila terdapat satu cluster akan melebihi kapasitas maksimal kendaraan.

- Jika hal tersebut terjadi maka dilakukan pembuatan cluster baru seperti langkah sebelumnya.

b. Tahap pembentukan rute distribusi

Tahap pembentukan rute distribusi, dari tiap cluster akan diselesaikan dengan metode Nearest Neighbour sehingga didapatkan diperoleh rute perjalanan dari tiap cluster. Langkah-langkahnya adalah sebagai berikut:

- Langkah inisiasi

- Menentukan satu titik sebagai titik awal perjalanan yaitu dari depot perusahaan

- Menentukan himpunan titik (C) yang akan dikunjungi oleh kendaraan.

- Menentukan urutan rute distribusi sementara.

- Memilih titik selanjutnya yang dikunjungi kendaraan.

Jika $n_{1}$ adalah titik di urutan terakhir dari rute $R$ maka titik berikutnya $n_{2}$ yang memiliki jarak paling minimum dengan $n_{1}$, dimana $n_{2}$ adalah anggota dari $C$. Apabila banyak pilihan optimal berarti terdapat lebih dari satu titik dengan jarak yang sama dari titik terakhir dalam rute $R$ dan jarak tersebut merupakan jarak yang paling minimum maka pilih secara acak. 
- Menambahkan titik terpilih untuk urutan rute berikutnya

Menambahkan titik $n_{1}$ pada urutan akhir rute sementara dan mengeluarkan titik yang terpilih dari daftar titik yang belum dikunjungi.

- Apabila semua titik telah dilewati selanjutnya dilakukan penutupan rute dengan menambahkan titik inisiasi atau titik awal perjalanan di akhir rute.

\section{METODE PENELITIAN}

Tahap metode penelitian yang dilakukan dalam penelitian ini berupa tahap pengumpulan data, dan dilanjutkan dengan pengolahan data, tahap penerapan metode, serta tahap terakhir adalah implementasi algoritma palgunadi.

\section{Pengumpulan data}

Metode pengumpulan yang digunakan adalah observasi langsung ke perusahaan mengenai sistem distribusi yang diterapkan pada koran harian Solopos dan wawancara kepada beberapa pihak yang bersangkutan. Dalam penelitian ini, data yang digunakan diantaranya adalah jumlah armada, kapasitas armada untuk pengiriman, jumlah agen koran Solopos dan lokasi agen, serta waktu service di tiap agen. Dalam penelitian ini hanya berfokus pada distribusi agen koran yang berada di wilayah Kartasura-Klaten saja.

\section{Pengolahan data}

Pengolahan data yang didapatkan menggunakan bantuan aplikasi google maps untuk mengetahui waktu tempuh yang dibutuhkan serta letak-letak antar agen. Namun di asumsikan apabila dalam pengantaran dan penjemputan koran harian tanpa mengalami kendala apapun dengan lalu lintas yang lancar.

\section{Penerapan metode}

Selanjutnya diterapkan analisis algoritma sweep sesuai dengan tahapan yang telah dijelaskan sebelumnya.

\section{PEMBAHASAN}

Data yang digunakan untuk penelitian ini berupa data distribusi harian Solopos bulan Febuari 2017 untuk wilayah Kartasura-Klaten ditampilkan pada tabel 1. Dipilih cakupan wilayah ini karena memiliki perentase penjualan harian Solopos wilayah Solo
Raya dengan nilai paling rendah yaitu sebesar $41 \%$. Nilai ini jauh dibawah wilayah Karanganyar sebesar $45 \%$, Sragen 48\%, dan Sukoharjo-Wonogiri-Karanganyar sebesar $49 \%$. Diketahui untuk proses distribusi harian Solopos wilayah Kartasura-Klaten menggunakan 1 buah armada yang memiliki kapasitas sekitar 3000 eksemplar. Armada ini digunakan sebagai sarana transportasi distribusi harian Solopos ke 9 depot/agen yang dimiliki. Banyaknya demand harian Solopos tiap agen berbeda-beda berkisar antara 189 hingga 995 dalam bulan febuari 2017. Dengan tingkat return yang berbeda pula. Distribusi harian Solopos setiap hari dimulai dari pukul 03.00 dini hari dan berakhir pada pukul 08.00 pagi dengan lama service time untuk 50 eksemplar koran selama 1 menit.

Tabel 1. Data demand, return, time windows

\begin{tabular}{|c|l|c|c|c|}
\hline Agen & $\begin{array}{c}\text { Nama } \\
\text { Agen }\end{array}$ & Demand & Return & $\begin{array}{c}\text { Time } \\
\text { windows }\end{array}$ \\
\hline A1 & Abdul basyir & 189 & 110 & 3,78 \\
\hline A2 & Yudistira & 270 & 210 & 5,4 \\
\hline A3 & Icah & 830 & 445 & 16,6 \\
\hline A4 & Sulomo & 560 & 170 & 11,2 \\
\hline A5 & Handoyo/wardoyo & 700 & 522 & 14 \\
\hline A6 & Multimediawara & 540 & 412 & 10,8 \\
\hline A7 & Ibra & 204 & 65 & 4,08 \\
\hline A8 & Handayani & 995 & 275 & 19,9 \\
\hline A9 & Sami & 405 & 405 & 8,1 \\
\hline
\end{tabular}

Adapun waktu tempuh tiap agen dari lokasi ditampilkan pada tabel 2. Waktu tempuh tersebut didapatkan melalui google maps dengan cara memasukkan data alamat agen yang telah diperoleh dari perusahaan. Sedangkan lokasi dan jarak agen dengan titik awal penyebaran distribusi ditampilkan pada tabel 3 .

Tabel 2. Matriks waktu tempuh antar agen wilayah Kartasura-Klaten (dalam menit)

\begin{tabular}{c|c|c|c|c|c|c|c|c|c|c} 
& Depot & A1 & A2 & A3 & A4 & A5 & A6 & A7 & A8 & A9 \\
\hline Depot & 0 & 16 & 19 & 29 & 27 & 38 & 48 & 49 & 46 & 50 \\
\hline A1 & 16 & 0 & 6 & 16 & 21 & 25 & 34 & 36 & 35 & 37 \\
\hline A2 & 19 & 6 & 0 & 16 & 25 & 25 & 34 & 36 & 35 & 37 \\
\hline A3 & 29 & 16 & 16 & 0 & 20 & 9 & 19 & 20 & 19 & 22 \\
\hline A4 & 27 & 21 & 25 & 20 & 0 & 24 & 34 & 35 & 33 & 36 \\
\hline A5 & 38 & 25 & 25 & 9 & 24 & 0 & 13 & 14 & 12 & 16 \\
\hline A6 & 48 & 34 & 34 & 19 & 34 & 13 & 0 & 2 & 5 & 8 \\
\hline A7 & 49 & 36 & 36 & 20 & 35 & 14 & 2 & 0 & 7 & 7 \\
\hline A8 & 46 & 35 & 35 & 19 & 33 & 12 & 5 & 7 & 0 & 5 \\
\hline A9 & 50 & 37 & 37 & 22 & 36 & 16 & 8 & 7 & 5 & 0 \\
\hline
\end{tabular}

Maka dilakukan proses pengelompokkan (clustering) dan dihasilkan dua cluster yaitu cluster I yang berisi agen A1, A2, A3, A4, A5 dan cluster II yang berisi agen A6, A7, A8, A9. Selanjutnya dilakukan tahap pembentukan rute masing-masing cluster dengan bantuan google maps seperti gambar 1 Dan dihasilkan rute distribusi harian Solopos sesuai cluster yang telah dibuat pada tabel 4 . 
Tabel 3. Lokasi dan jarak agen dengan titik awal penyebaran distribusi

\begin{tabular}{|l|l|c|}
\multicolumn{1}{|c|}{ Nama Agen } & \multicolumn{1}{c|}{ Lokasi } & Jarak dari depot \\
\hline Abdul basyir & Sedahromo Lor Kartasura & $8,9 \mathrm{Km}$ \\
\hline Yudistira & Tisanan wirogunan kartasura & $11,2 \mathrm{Km}$ \\
\hline Icah & Kios mayungan trunuh klaten & $38,2 \mathrm{Km}$ \\
\hline Sulomo & Jalan Raya Delanggu & $20,3 \mathrm{Km}$ \\
\hline Handoyo/wardoyo & Karangwuni ceper klaten & $28,3 \mathrm{Km}$ \\
\hline Multimediawara & Kios pasar srago klaten & $35,1 \mathrm{Km}$ \\
\hline Ibra & Jalan RA Kartini klaten & $36,2 \mathrm{Km}$ \\
\hline Handayani & Jalan RA Kartini klaten & $34,9 \mathrm{Km}$ \\
\hline Sami & Terminal klaten & $35,8 \mathrm{Km}$ \\
\hline
\end{tabular}
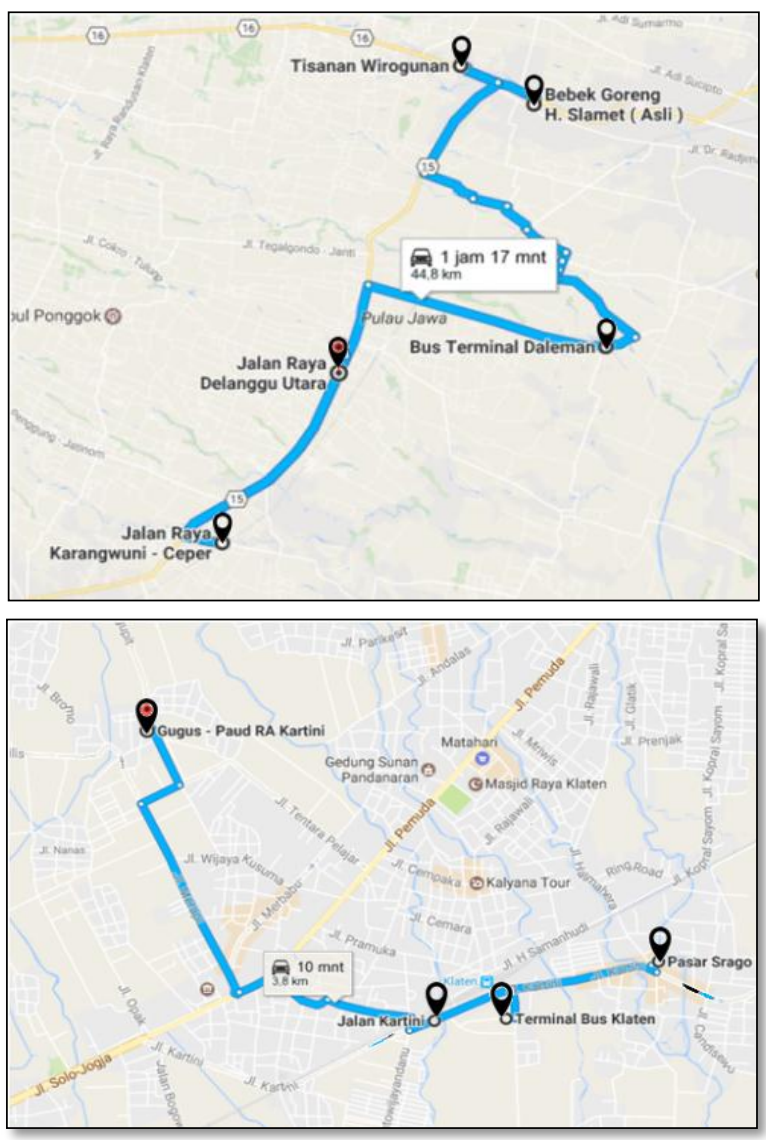

Gambar 1. Penentuan cluster dengan bantuan google maps

Tabel 4. Rute distribusi harian Solopos yang terbentuk

\begin{tabular}{c|c|c}
\hline No & Rute & Junlah \\
\hline 1 & $\begin{array}{c}\text { Depot-A1-A2-A3-A4- } \\
\text { A5-Depot }\end{array}$ & 2144 \\
\hline 2 & $\begin{array}{c}\text { Depot-A7-A6-A9-A8- } \\
\text { Depot }\end{array}$ & 2549 \\
\hline
\end{tabular}

Berdasarkan penyelesaian dengan algoritma sweep maka didapatkan rute dengan total waktu tempuh dan jarak tempuh sebagai berikut:

\begin{tabular}{c|c|c}
\hline & Rute 1 & Rute 2 \\
\hline & $\begin{array}{c}\text { Depot-A1-A2-A3-A4-A5- } \\
\text { Depot }\end{array}$ & Depot-A7-A6-A9-A8-Depot \\
\hline Jarak tempuh & $72,2 \mathrm{Km}$ & $71,8 \mathrm{Km}$ \\
\hline $\begin{array}{c}\text { Waktu tempuh } \\
\text { total }\end{array}$ & 3 jam 9 menit & 2 jam 46 menit \\
\hline
\end{tabular}

\section{KESIMPULAN}

Berdasarkan penyelesaian Capacited Vehicle Routing Problem dengan algoritma sweep untuk optimasi rute distribusi harian Solopos didapatkan dua rute berdasarkan pengelompokkan yang telah dilakukan dengan waktu tempuh total kedua rute selama 5 jam 55 menit sesuai dengan kebijakan time windows yang diterapkan perusahaan.

\section{DAFTAR PUSTAKA}

Aranganayaki, "Reduce Total Distance and Time Using Genetic Algorithm in Travelling Salesman Problem," International Journal of Computer Science \& Engineering Technology (IJCSET), vol. 5, no. 08, pp. 816, 2014.

Gunawan, Indra Maryati, dan Henry Kurniawan W., "Optimasi Penentuan Rute Kendaraan Pada Sistem Distribusi Barang dengan Ant Colony Optimization," Seminar Nasional Teknologi Informasi \& Komunikasi Terapan, Surabaya: Sekolah Tinggi Teknik Surabaya, 2012.

Hijri Virgiawan, "Aplikasi Vehicle Routing Problem Pada Penentuan Rute Distribusi Air Mineral Club di Kota Balikpapan," Skripsi, FT-Universitas Mulawarman, 2014.

Ballou, R.H, Bussiness Logistics/Supply Chain Management Fifth Edition, Pearson Education International, Ohio, 2005.

Gladiez Florista Rera dan Budi Santosa, "Penerapan Metode Cross Entropy Dalam Penyelesaian Capacitated Vechile Routing Problem (Studi kasus : distribusi koran Jawa Pos Surabaya".

Gunadi W. Nurcahyo, Rose Alinda Alias, SM Mamyam Shamsuddin \& Mohd. Noor MD. SAP, "Sweep Algorithm in Vehicle Routing Problem For Public Transport," Jurnal Antarbangsa (Teknologi Maklumat), vol.2, pp. 51-64, 2002.

Sri Basriati dan Rio Sunarya, "Oprimasi Distribusi Koran Menggunakan Metode Saving Matriks (Studi Kasus: PT. Riau Pos Intermedia), Seminar Nasional Teknologi Informasi, Komunikasi dan Industri (SNTIKI) 7, 448-453, 2011

Wahyudi K Cahyaningsih, Eminugroho Ratna Sari, Kuswari Hernawati. "Penyelesaian Capacitated Vechile Routing Problem (CVRP) Menggunakan Algoritma Sweep Untuk Optimasi Rute Distribusi Surat Kabar Kedaulatan Rakyat," Seminar Nasional Matematika dan Pendidikan Matematika UNY, 2015. 